\title{
Генерация частотной гребёнки на основе многопроходного акусто-оптического модулятора с ультрастабильной частотой модуляции
}

\author{
С.Н. Атутов \\ ИАиЭ СО РАН, Новосибирск \\ *E-mail: atutov@fe.infn.it
}

DOI:10.31868/RFL2018.187

В докладе изложены результаты экспериментов по генерации частотного гребня (frequency comb) с управляемым резким краем (sharp edge). Частотный гребень генерируется посредством последовательных сдвигов частоты одночастотного лазера с помощью акустооптического модулятора (AОM), встроенного в пассивный оптический резонатор. Конструкция устройства имеет очень высокую эффективность и обеспечивает идеальное управление, как частотой, так и положением резкого края. Использовался второй акустооптический модулятор для удвоения ширины частотного гребня. Частотная стабильность резкого края обеспечивается стабилизированным одночастотным лазером и стабильным АОМ питаемым кварцевым генератором или квантовым стандартом частоты. Обсуждается возможность компенсации потерь в пассивном резонаторе устройства с помощью включения в резонатор усиливающей среды волоконных лазеров, что позволит распространить частотную стабильность использованного лазера и АОМ со стабильностью квантового стандарта частоты в диапазоне по длине волны порядка 1000 - 1500 нм в инфракрасной области спектра.

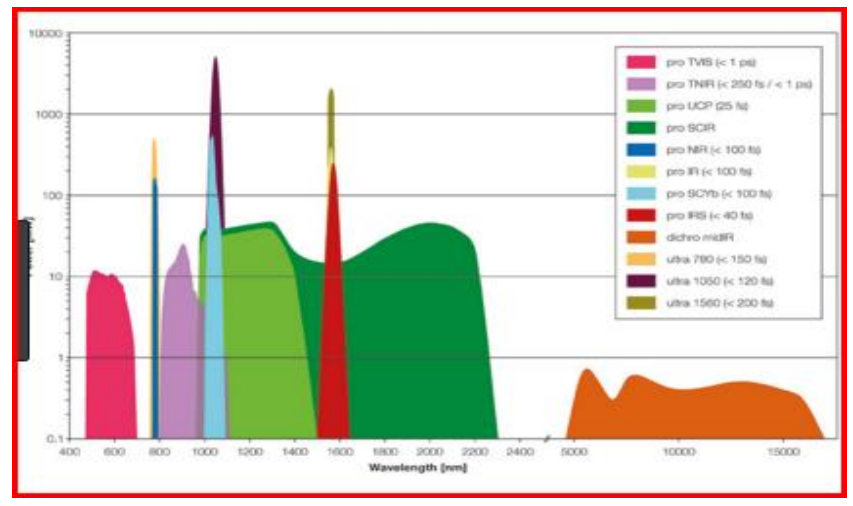

S.N. Atutov et al. / Sharp edge broad-band lasers for "white-light" cooling

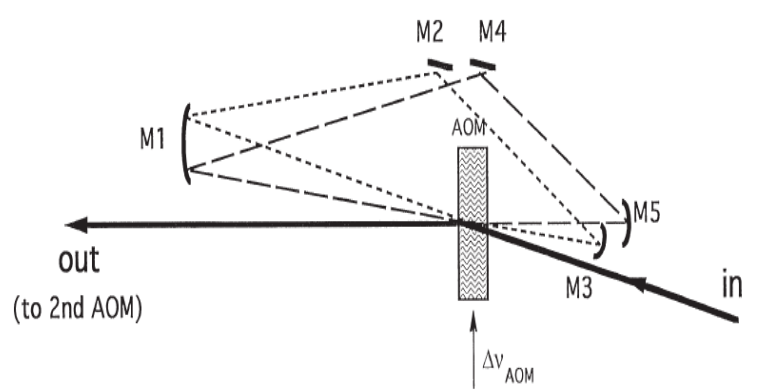

Sketch of the cavity configuration. $\mathrm{M}_{1-5}=$ mirrois; the arrow shows the direction of the acoustic wave
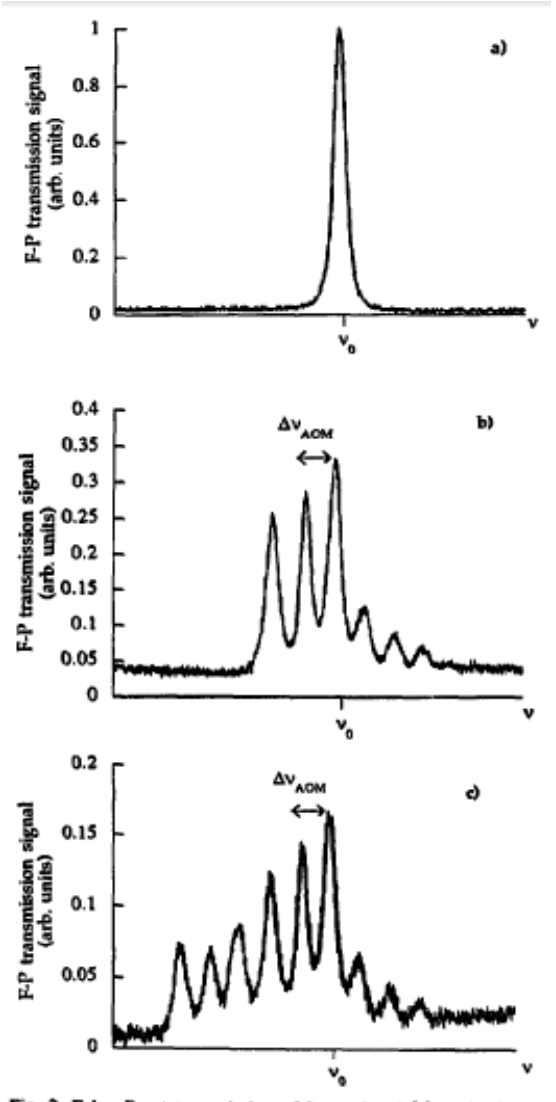

Fig. 2. Fabry-Perot transmission of laser signal (a) cavity inpout (b) cavity output; (c) output from the second AOM. The values are normalized to input intensity. 